\title{
Oleic acid-based poly(alkyl methacrylate) as bio-based viscosity control additive for mineral and vegetable oils
}

\author{
Juliette Lomège, Claire Negrell, Jean-Jacques Robin, Vincent Lapinte, Sylvain Caillol* \\ ICGM, UMR 5253 - CNRS, Université de Montpellier, ENSCM, 240 Avenue Emile Jeanbrau 34296 Montpellier, France
}

*Correspondence:

Sylvain Caillol, ICGM, UMR 5253 - CNRS, Université de Montpellier, ENSCM, 240 Avenue Emile Jeanbrau 34296 Montpellier 34296 Montpellier, France Email: sylvain.caillol@enscm.fr

Running Title: Oleic acid-based poly(alkylmethacrylate) as bio-based viscosity modifiers for mineral and vegetable oils

Keywords: Oleic acid; methacrylate monomer; radical polymerization; oil-polymer blends; viscosimetry; rheology

Abbreviations: SEC, size exclusion chromatography, DSC, differential scanning calorimetry, TGA, thermogravimetric analysis, NMR, nuclear magnetic resonance, MPO, mineral paraffinic oil, OTO, organic tiglyceride oil, MAEO, 2-(methacryloyloxy)ethyl oleate, PMAEO, poly(2-(methacryloyloxy)ethyl oleate)

\begin{abstract}
This work described the design of an efficient oleic-acid based viscosity control additive for lubricating oils as potential alternative to petroleum poly(alkyl)methacrylates (PAMAs) additives. Hence, Poly(2(methacryloyloxy)ethyl oleate) (PMAEO) was synthesized by free radical homopolymerization to afford a comblike polymer structure similar to common PAMAs. Then, in order to evaluate its efficiency as viscosity control additive, the resulting polymer was mixed at several concentrations from $1 \%$ wt to $10 \%$ wt with different oil compositions, including a mineral paraffinic oil (MPO) and an organic triglyceride oil (OTO). For all polymersolution blends, relative viscosities (RV) measurements showed that addition of PMAEO in MPO had a better contribution on oil viscosity at $100^{\circ} \mathrm{C}$ than at $20^{\circ} \mathrm{C}\left(R V=1.16\right.$ at $40^{\circ} \mathrm{C}$ while $R V=1.25$ for $3 \%$ wt of PMAEO in MPO). These results were attributed to the coil expansion of polymer chains with increasing temperature. Additionally, rheological studies showed that addition of 3\%wt of PMAEO in MPO improved the MPO cold flow properties at $-30^{\circ} \mathrm{C}$ by decreasing the required yield stress to put the oil in motion from $310 \mathrm{mPa}$ to $42 \mathrm{mPa}$. These results are in total accordance with the common viscosimetric properties of PAMAs-based viscosity control additives at low and high temperature in mineral oils.
\end{abstract}

\section{Graphical abstract}




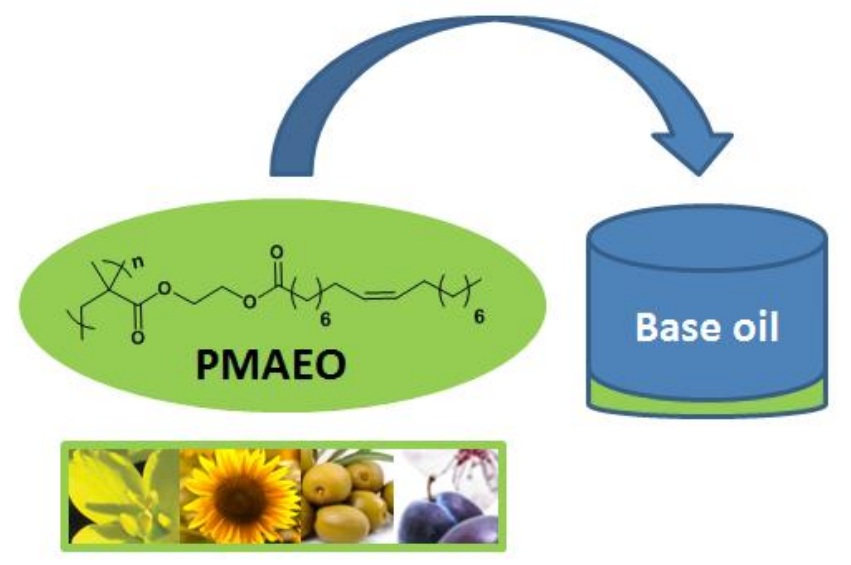

\section{Introduction}

The scarcity of petroleum resources, the dangerousness of some of these products in a sustainable development context are prompting researchers towards the synthesis of more environmentally-friendly polymers, especially from renewable resources. ${ }^{1}$ Due to recent advances in lipid science, agricultural technology and oleochemistry, ${ }^{2,3}$ fatty acids (FA) appear as one of the most interesting feedstock alternative to petroleum resources. ${ }^{4-11}$ In the spotlight of chemical industry, FA success over the last few years is explained by several advantages such as their ready availability, reduced ecotoxicity and toxicity, biocompatibility, low volatility as well as their attractive cost. ${ }^{12}$ Additionally, FA contain reactive sites, particularly the carboxylic acid and the double bond for unsaturated FA, opening up various possibilities of functionalization to tailor new bio-based monomers. For instance, FA and their derivatives can be easily functionalized with hydroxyl, acid, epoxy or amine groups to afford various bio-based polymers. ${ }^{10,13-16}$ However, even if most current VO-based monomers are suitable for polycondensation, only a handful of them are reported for radical polymerization, whereas many common polymers are industrially obtained by this process. ${ }^{17-19}$ For instance, poly(alkyl (meth)acrylate)s (PAMAs) have been widely used since the beginning of the $20^{\text {th }}$ century and constitute one of the most important family of polymers obtained by radical polymerization. ${ }^{20}$ The

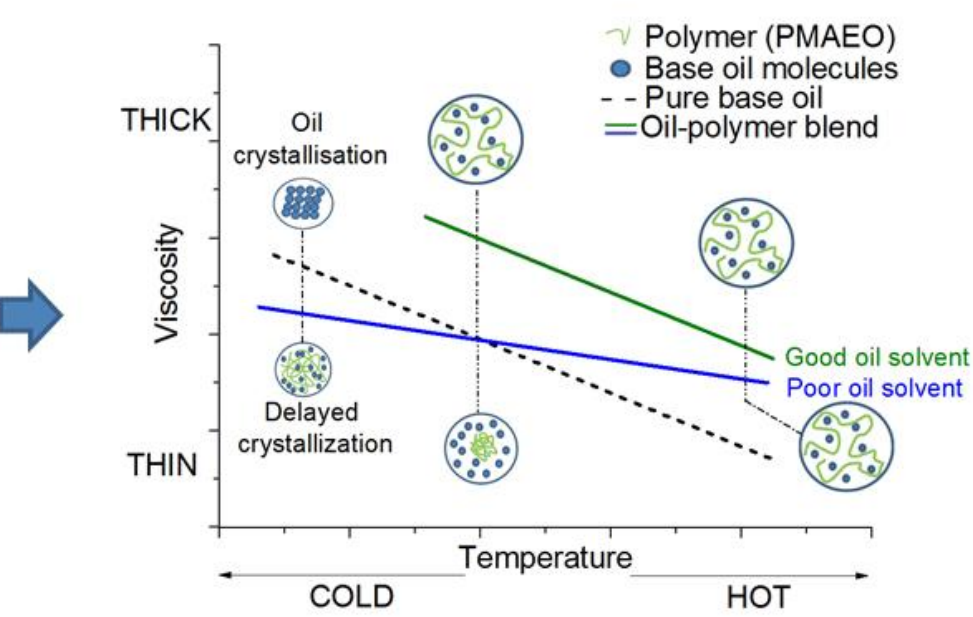

widespread use of PAMAs is attributed to their high versatility allowing them to meet a wide range of applications such as adhesives, ${ }^{21}$ waterborne coatings $^{22}$ and more particularly as additives for lubricating oils. ${ }^{23}$ Indeed, PAMAs have the ability to considerably reduce the viscosity-temperature dependency of mineral oils. ${ }^{24}$ Based on the coil expansion theory, such polymers are able to expand with temperature and to coil up with decreasing temperature. ${ }^{25,26}$ Consequently, in mineral oils these polymers exhibit a negligible viscosity contribution at low temperature while providing a large viscosity contribution at high temperature. Hence, they are currently used in lubricant industry to effectively thicken mineral oils as temperature increases and thus, improved their operating temperature range. In addition, PAMAs enhance the flow properties of mineral oils by delaying wax crystallization process which naturally occurs in such oils when temperature decreases. ${ }^{27-32}$ Except for some patents that report the synthesis of acrylic acid from glycerol, ${ }^{33}$ the most common PAMAs come from petroleum. Considering advances in the use of PAMAs which have opened up a wide range of applications, and more especially in lubricant industry, there is an important environmental challenge in synthesizing new biobased methacrylate monomers.

Hence, FA can be excellent candidates to design biobased (meth)acrylate monomers considering all their advantages mentioned before. In addition, they are also known to have natural lubricating properties and their long aliphatic chain combined with their polar head reminds the structure of petroleum methacrylate monomers used for the synthesis of PAMAs. This specific chemical structure guarantees 
them a good compatibility in lubricating oils. However, FA are not reactive through radical polymerization due to their low reactivity. In order to overcome this drawback, some research groups focused on the copolymerization of vegetable oils with a more reactive co-monomer to provide suitable additives for lubricating oil. ${ }^{34}$ However, FA could be also functionalized with (meth)acrylate moieties to overcome their poor reactivity in radical polymerization. ${ }^{35-41}$ For instance, Maiti et al. have reported a one-step synthesis method based on Steglich esterification of various fatty acids with 2hydroxyethyl methacrylate (HEMA). ${ }^{37,42}$ Various potential practical applications were proposed for the resulting macromolecular architectures including paints, adhesives, electricals insulators, thermoplastics or nano-objects for drug delivery but no specific application was studied yet through their work. Such comb-like structures with long aliphatic chains may appear as promising viscosity modifier polymers for lubricating oils.

Therefore, the objective of this work was to synthesize a methacrylate comb-like polymer with a fatty acid side chains with potential application as viscosity control additive in lubricating oils. Oleic acid was chosen as starting materials for this study considering its wide abundance in various vegetables oils and its attractive cost. ${ }^{43}$ Hence, oleic acid was functionalized by Steglich esterification with HEMA to afford a partially bio-based methacrylate monomer which was then efficiently involved in free radical polymerization. The resulting polymer was added in a mineral paraffinic oil (MPO) and in an organic triglyceride oil (OTO) at different polymer concentrations and then evaluated as viscosity modifier additive. For this purpose, a detailed rheological study was performed on oil-polymer blends in order to better understand the polymer influence on oils viscosity with temperature.

\section{Materials and methods}

\section{1- Reagents}

Oleic acid (OA, 98\% pure) was obtained from Fisher Scientific while all other reagents were purchased from Sigma-Aldrich. Dicyclohexylcarbodiimide (DCC), $4-$ dimethylaminopyridine (DMAP), 2-hydroxyethyl methacrylate (HEMA), benzoyl peroxide (BPO), deuterated solvent $\mathrm{CDCl}_{3}$, tetrahydrofuran (THF), toluene, methanol ( $\mathrm{MeOH})$, ethyl acetate (EtOAc) and cyclohexane were used as received. The purity of all mentioned products is superior to $98 \%$.

Commercial mineral paraffinic oil (MPO) and organic triglyceride oil (OTO) were kindly supplied by ITERG and CHEVRON LURBICANT respectively. Their viscosimetric properties from $20^{\circ} \mathrm{C}$ to $100^{\circ} \mathrm{C}$ are summarized in Erreur! Source du renvoi introuvable..

\section{INSERT TABLE 1}

\section{2- Instrumentations}

\section{Nuclear magnetic resonance (NMR)}

${ }^{1} \mathrm{H}$ NMR spectra were acquired at room temperature using a Bruker Advance $400 \mathrm{MHz}$ spectrometer equipped with a QNP z-gradient probe. NMR samples were prepared by dissolving $10 \mathrm{mg}$ of product in around $0.4 \mathrm{~mL}$ of $\mathrm{CDCl}_{3}$. The chemical shifts were reported in part per million relative to tetramethylsilane. Spin multiplicity is shown by $s=$ singlet, $\mathrm{d}=$ doublet, $\mathrm{t}=$ triplet, $\mathrm{q}=$ quartet, $\mathrm{m}=$ multiplet.

\section{Size exclusion chromatography (SEC)}

Molar mass and molar mass dispersity $(\boxplus)$ of polymers were determined by size exclusion chromatography using a GPC 50 Varian equipped with an $\mathrm{RI}$ refractive index detector. The system used two PLgel $5 \mu \mathrm{m}$ Mixed D columns with THF as eluent with a flow rate of $1 \mathrm{~mL} \cdot \mathrm{min}^{-1}$. Poly (methyl methacrylate) (PMMA) standards were used for the calibration. The typical sample concentration was 5 $\mathrm{mg} \cdot \mathrm{mL}^{-1}$.

\section{Thermogravimetric analysis (TGA)}

Thermogravimetric analyses (TGA) were performed using a TGA Q50 (TA instrument) at a heating rate of $10^{\circ} \mathrm{C} / \mathrm{min}$. Approximately $10 \mathrm{mg}$ of sample was placed in an aluminum pan and heated from room temperature to $500{ }^{\circ} \mathrm{C}$ under nitrogen atmosphere $\left(60 \mathrm{~mL} \cdot \mathrm{min}^{-1}\right)$ 
Differential scanning calorimetry (DSC)

Differential scanning calorimetry (DSC) analyses were carried out using a NETZSCH DSC200F3 calorimeter. Constant calibration was performed using indium, noctadecane and n-octane standards. Nitrogen was used as the purge gas. 10-15 mg samples were sealed in aluminum pans. The thermal properties were analyzed at $20^{\circ} \mathrm{C} / \mathrm{min}$ in the range between 100 and $100{ }^{\circ} \mathrm{C}$.

\section{Viscosimetric measurements}

All measurements were performed on a Lovis 2000 $\mathrm{M} / \mathrm{ME}$ rolling ball viscometer with a standard deviation inferior to $0.1 \%$. The oil-polymer blends were all stirred at $40{ }^{\circ} \mathrm{C}$ for $30 \mathrm{~min}$ to ensure a good homogenization and cooled at the temperature of measurement before starting any measurement. The solution containing polymer flows through a given length of glass capillary and the time $(t)$ taken for a given volume to pass through is compared to the time $\left(t_{0}\right)$ taken by the solvent without polymer. As such, the relative viscosity is calculated using the equation (1) above:

$$
\eta_{r}=\frac{\eta}{\eta_{0}} \simeq \frac{t}{t_{0}} \quad(\text { Equation } 1)
$$

Where $\eta$ and $\eta_{0}$ correspond respectively to the relative viscosity of the polymer solution and that of the pure solvent. Others viscosimetric parameters such as specific viscosity (equation 2), reduced viscosity (equation 3 ) were calculated to measure intrinsic viscosity of each polymer solution using Martin equation (equation 4):

$$
\begin{gathered}
\eta_{s p}=\frac{\eta-\eta_{0}}{\eta_{0}}=\eta_{r}-1 \quad(\text { Equation 2) } \\
\eta_{\text {red }}=\frac{\eta_{s p}}{c} \quad(\text { Equation 3) }
\end{gathered}
$$

Where $\mathrm{c}$ is the concentration of the solute

$$
\text { Martin equation: }[\eta]_{M}=\lim _{c \rightarrow 0}\left(\ln \left(\eta_{\text {red }}\right)\right)
$$

(Equation 4)

Intrinsic viscosity ([n]) was graphically measured by extrapolating the plot of the logarithm of the reduced viscosity $\left(\ln \left(\eta_{\text {red }}\right)\right.$ to zero concentration.

\section{Rheological measurements}

The rheological measurements were performed on a modular compact rheometer MCR 302 equipped with a coaxial cylinder system and thermostated cooling system. These rheological tests were carried out at 20 and $-30^{\circ} \mathrm{C}$. The rheological behavior of oilpolymer blends was determined through measurements of shear stress $(\mathrm{Pa})$ and dynamic viscosity (Pa.s) at various shear rates (1/s). From these measurements, yield stress ( $\mathrm{Pa})$ was graphically measured by extrapolating the shear stress to zero shear rate on a linear plot.

\section{3- Synthesis of MAEO monomer}

Oleic acid ( $80 \mathrm{mmol}, 21.17 \mathrm{~g})$ and DMAP $(40 \mathrm{mmol}$, $4.59 \mathrm{~g}$ ) were dissolved in $48 \mathrm{~mL}$ of THF in $250 \mathrm{~mL}$ two neck round bottom flask equipped with a magnetic stirring bar. Then, HEMA (150 mmol, $19.54 \mathrm{~g}$ ) was added to the mixture and the flask was put in icewater bath with a purge of $\mathrm{N}_{2}$ gas through it. In a beaker, DCC was dissolved in minimum volume of THF and was added dropwise to the reaction mixture at $0{ }^{\circ} \mathrm{C}$. The ice-water bath was removed after addition of DCC. The resulting mixture was stirred for $24 \mathrm{~h}$ at room temperature. At the end of the reaction, precipitated urea is filtered off and the solvent was removed by rotary evaporator. The resulting ester is purified by column chromatography using silica gel as stationary phase and cyclohexane-EtOAc (95:5, $\mathrm{v} / \mathrm{v}$ ) as an eluent to yield pure monomer MAEO (yield $=67 \%$ ). Its chemical structure was confirmed by ${ }^{1} \mathrm{H}$ NMR (400 MHz, $\mathrm{CDCl}_{3}$ ). $\delta$ (ppm): 6.12 and 5.59 $\left(\mathrm{C}=\mathrm{CH}_{2}, 2 \mathrm{H}, \mathrm{d}\right), 5.34 \quad(-\mathrm{CH}=\mathrm{C} \underline{\mathrm{H}}-, \quad 2 \mathrm{H}, \mathrm{m}), 4.33$ $\left(\mathrm{OC} \underline{\mathrm{H}}_{2} \mathrm{C}_{2} \mathrm{O}, 4 \mathrm{H}, \mathrm{t}\right), 2.01\left(\mathrm{C}_{2}{ }_{2} \mathrm{CH}=\mathrm{CHC} \underline{\mathrm{H}}_{2}, 4 \mathrm{H}, \mathrm{m}\right), 2.32$ $\left(\mathrm{O}=\mathrm{CC}_{2}, 2 \mathrm{H}, \mathrm{t}\right), 1.62\left(\mathrm{O}=\mathrm{CCH}_{2} \mathrm{CH}_{2}, 2 \mathrm{H}, \mathrm{m}\right), 1.29$ ($\left.\left(\mathrm{C}_{2}\right)_{6}-\mathrm{CH}_{2}-\mathrm{CH}=\mathrm{CH}-\underline{\mathrm{C}}_{2}-\left(\mathrm{C}_{2}\right)_{4^{-}}, \quad 2 \mathrm{OH}, \mathrm{m}\right), \quad 1.94$ $\left(\mathrm{CH}_{2}=\mathrm{CH}-\underline{\mathrm{C}}_{3}, 3 \mathrm{H}, \mathrm{s}\right), 0.87\left(-\mathrm{CH}_{2} \mathrm{CH}_{3}, 3 \mathrm{H}, \mathrm{t}\right)$. All peaks have been assigned on ${ }^{1} \mathrm{H}$ NMR spectrum as illustrated in Scheme 1, Step A.

\section{4- Synthesis of PMAEO by free radical polymerization}

Homopolymerization of MAEO was carried out in anhydrous toluene at $90{ }^{\circ} \mathrm{C}$ by using BPO as radical source. The typical protocol is described as follows: MAEO (10.14 mmol, $4 \mathrm{~g}$ ) and BPO (0.3 mmol, $74 \mathrm{mg})$ were dissolved in $10.8 \mathrm{~mL}(0.1 \mathrm{~mol}, 9.33 \mathrm{~g})$ of dry 
toluene. The reaction mixture was then added into a two necked flask equipped with a magnetic bar and purged with $\mathrm{N}_{2}$ gas for $20 \mathrm{~min}$. The reaction mixture was put at $90{ }^{\circ} \mathrm{C}$ for $9 \mathrm{~h}$. Then, the mixture was quenched by cooling in liquid nitrogen and purified by precipitation in $\mathrm{MeOH}$ at least two times to yield a viscous liquid. The obtained polymer was dried under vacuum for $5 \mathrm{~h}$ at $80{ }^{\circ} \mathrm{C}$ (yield $=73 \%$ ). Its chemical structure was confirmed by ${ }^{1} \mathrm{H}$ NMR $(400 \mathrm{MHz}$, $\left.\mathrm{CDCl}_{3}\right) . \delta(\mathrm{ppm}): 5.34(-\mathrm{C} \underline{\mathrm{H}}=\underline{\mathrm{C}}-\mathbf{H}-2 \mathrm{H}, \mathrm{m}), 4.25-4.13$ $\left(\mathrm{OC}_{2} \mathrm{CH}_{2} \mathrm{O}, 4 \mathrm{H}, \mathrm{m}\right), 2.32\left(\mathrm{O}=\mathrm{CC}_{\underline{2}}, 2 \mathrm{H}, \mathrm{m}\right), 2.01$ $\left(\mathrm{C}_{2}{ }_{2} \mathrm{CH}=\mathrm{CHC}_{2}, 4 \mathrm{H}, \mathrm{m}\right), 1.82\left(-\mathrm{CH}_{2^{-}}, 2 \mathrm{H}, \mathrm{m}\right), 1.62$ $\left(\mathrm{O}=\mathrm{CCH}_{2} \mathrm{C}_{2}, 2 \mathrm{H}, \mathrm{m}\right), 1.29\left(-\left(\mathrm{C}_{2}\right)_{6}-\mathrm{CH}_{2}-\mathrm{CH}=\mathrm{CH}-\underline{\mathrm{C}}_{2}-\right.$ $\left.\left(\mathrm{C}_{2}\right)_{4^{-}}, 2 \mathrm{H}, \mathrm{m}\right), 1.03\left(\mathrm{C}_{3^{-}}, 3 \mathrm{H}, \mathrm{m}\right), 0.87\left(-\mathrm{CH}_{2} \mathrm{C}_{3}\right.$, $3 \mathrm{H}, \mathrm{t}$ ). All peaks have been assigned on ${ }^{1} \mathrm{H} N M R$ spectrum as shown in Scheme1, Step B.

\section{Results and discussion}

\section{Monomer synthesis and characterization}

MAEO was synthesized by Steglich esterification condensation of HEMA and oleic acid in the presence of DMAP as catalyst and DCC as coupling agent in THF at ambient temperature for $24 \mathrm{~h}$ (Figure 1, A). The structure of MAEO was confirmed by using ${ }^{1} \mathrm{H}$ NMR spectroscopy (in $\mathrm{CDCl}_{3}$ ) which allowed to assign all the resonance signals (Scheme1, Step A). In the ${ }^{1} \mathrm{H}$ NMR spectrum of MAEO, the signal at $5.34 \mathrm{ppm}$ corresponded to the unsaturations of oleate sidechain while the vinyl protons of the methacrylate function were assigned to the peaks at 6.12 and 5.59 ppm. No side reaction from the oleate double bonds were observed which confirms the effectiveness of the synthesis procedure.

\section{INSERT SCHEME 1}

\section{Polymer synthesis and characterization}

The polymerization of MAEO was performed in toluene at $90{ }^{\circ} \mathrm{C}$ in presence of $\mathrm{BPO}$ as initiator (Scheme 1, Step B). ${ }^{1} \mathrm{H}$ NMR data revealed a moderate rate of polymerization with $84 \%$ of monomer conversion after $7 \mathrm{~h}$ of reaction as shown in Figure 2. The limited conversion may be attributed to the increasing viscosity in the system after reaching a certain conversion level which induced the slowing down mobility of the monomer and the initiator. This can be also combined with the gradual disappearance of radicals in the system as reaction proceeded. In ${ }^{1} \mathrm{H}$ NMR spectrum of PMAEO, the peaks assigned to the vinylic protons of methacrylate moiety had disappeared, which indicated complete removal of unreacted monomer after precipitation in cold methanol (Figure 1, B). The peaks of the oleic double bond at $5.34 \mathrm{ppm}$ remained constant in the polymer spectrum, which reveals its unreactivity during the polymerization process. The ethylene oxide protons $(4 \mathrm{H})$ of the polymer side chain appeared at 4.13-4.24 ppm while methyl protons of the backbone of the polymer are assigned to the peak at $1.02 \mathrm{ppm}$.

Number average molar mass $\overline{\mathrm{Mn}}(\mathrm{g} / \mathrm{mol})$ and dispersity $(\boxminus)$ of PMAEO were determined by gel permeation chromatography (SEC). It exhibited a wide dispersity (3.6) and a molar mass of 45,000 $\mathrm{g} / \mathrm{mol}$.

According to TGA analysis (Figure 1, SI). PMAEO exhibited a good thermal stability up to $265^{\circ} \mathrm{C}$. From the DSC analysis, the polymer showed a glass transition temperature at $-80^{\circ} \mathrm{C}$ without crystallinity between -100 and $100{ }^{\circ} \mathrm{C}$ (Figure 2, SI). Hence, PMAEO can be used as additive in oil over a wide range of temperatures.

\section{INSERT FIGURE 1 INSERT FIGURE 2}

\section{Viscosimetric characterization}

This study was conducted to evaluate the ability of PMAEO to follow the coil expansion theory as conventional PAMA in various lubricating oils. This rheological behavior will confirm their efficiency as viscosity control additive. Based on kinematic viscosity data of various oil-polymer blends at different temperatures and concentrations (Erreur ! Source du renvoi introuvable.), relative viscosities of each blend were calculated through viscometer measurements and plotted against temperature (Figure 3 for MPO ; Figure 5 for OTO). In case of coil expansion, the relative viscosity which represents the influence of polymer on oil viscosity should increases with temperature. ${ }^{26}$ However, rather different behaviors of PMAEO coil with temperature were observed according to the oil composition. 


\section{INSERT TABLE 2 \\ INSERT FIGURE 3}

For PMAEO-MPO blends, the relative viscosity tends to increase with temperature especially for high PMAEO concentrations between 20 and $100^{\circ} \mathrm{C}$ supposing a coil expansion of polymer chains in oil (Figure 6). For instance, at $5 \%$ wt of PMAEO in MPO, relative viscosity increases from 1.12 at $20^{\circ} \mathrm{C}$ to 1.51 at $100^{\circ} \mathrm{C}$ suggesting a better thickening effect at high temperature. By contrast, for lower polymer concentration, the coil expansion is limited (1.03 at $20{ }^{\circ} \mathrm{C}$ and 1.07 at $100{ }^{\circ} \mathrm{C}$ ) and may due to a dilute regime inducing only few interactions between polymer chains and oil. In order to confirm the expansion of PMAEO's chains with temperature, the intrinsic viscosity of polymer in MPO was compared between 40 and $100{ }^{\circ} \mathrm{C}$ by plotting the reduced viscosity against temperature (Figure 4). A significant variation of intrinsic viscosity with temperature was observed with a value of $3.87 \mathrm{~mL} / \mathrm{g}$ at $40{ }^{\circ} \mathrm{C}$ and one of $6.65 \mathrm{~mL} / \mathrm{g}$ at $100{ }^{\circ} \mathrm{C}$. As intrinsic viscosity is proportional to the hydrodynamic volume of spherical polymer coil in solution according to Einstein's viscosity equation (Equation 5 ), ${ }^{26}$ it can be concluded that PMAEO coil expands in MPO with temperature in agreement with the Selby theory. ${ }^{25}$

$$
V e=\frac{[n] M_{w}}{2.5 N}(5)
$$

Where $V e, M_{w}$, and $N$ are respectively the hydrodynamic volume, the average molecular weight and Avogadro's number.

On the other hand, relative viscosity for PMAEO-OTO blends remains constant with temperature (Erreur ! Source du renvoi introuvable.). Thereby, these results demonstrate that the polymer coil size dimension was not affected by temperature. Consequently, the PMAEO coil expansion theory is not observed in OTO which may be related to a difference of polymer solubility according to the oil composition. The similarity of chemical structures between triglycerides contained in OTO and fatty ester contained in PMAEO may induce a high solubility of polymer in oil avoiding the coil expansion to proceed. Indeed, if the coil polymer is already swollen at low temperature due to the good polymer solvation, it limits the polymer chain expansion at higher temperature. Consequently, the PMAEO had a similar contribution on OTO's viscosity at each temperature inducing no improvement of relative viscosity with temperature. Hence, the polymer can be defined as a thickener additive when used in OTO. However, as MPO is a paraffinic oil with only saturated aliphatic hydrocarbons, the solubility of PMAEO is expected to decrease. Indeed, the polar ester functionality on PMAEO backbone is not wellsolvated in such oil and may induce a contraction of polymer chains at low temperature and thus a low effect on oil viscosity. This low polymer solubility in MPO is improved by increasing temperature which leads to a coil polymer expansion. This specific expanded coil conformation at high temperature induces higher oil viscosity contribution than at low temperature (Erreur! Source du renvoi introuvable.). This mechanism of action of PMAEO in MPO oil is in total accordance with the reported mechanism of action upon mineral oils viscosity for conventional petroleum PAMA. ${ }^{25}$ Hence, PMAEO represents an interesting bio-based alternative able to mimic the viscosimetric properties of PAMA additives in mineral oils.

\section{INSERT FIGURE 4 INSERT FIGURE 5 INSERT FIGURE 6}

\section{Rheological measurements}

MPO generally have poor cold flow properties due to crystallization of their wax content (hydrocarbon compounds) at low temperature..$^{29,31,41-43}$ This leads to a minimum operating point below which oil flow would be disturbed and will require more energy (i.e. high shear stress) to flow properly. ${ }^{47}$ Pretreatment with polymeric additive such as PAMA enhances MPO flow at low temperature. ${ }^{28,48,49}$ Rheological studies of oil-polymer blends can provide a direct overview of polymeric additive influence on the oil rheological behavior. ${ }^{50-52}$ Hence, the rheological behavior of both pure MPO and with $3 \%$ wt of PMAEO were determined through viscosimetric shear stress-shear rate and dynamic viscosity-shear rate measurements at room temperature and at low temperature $\left(-30^{\circ} \mathrm{C}\right)$.

According to Erreur ! Source du renvoi introuvable., PMAEO had a low thickening effect in MPO at $20^{\circ} \mathrm{C}$. 
The plot of dynamic viscosity against shear rate showed that at $1,000 \mathrm{~s}^{-1}$ shear rate, MPO had a dynamic viscosity of $41.7 \mathrm{mPa}$.s which was improved to $46.5 \mathrm{mPa}$.s with PMAEO addition. This limited viscosity contribution of polymer in oil suggested a contracted polymer conformation at $20{ }^{\circ} \mathrm{C}$ as demonstrated in the previous study. In accordance with this first observation, the initial rheological behavior of pure MPO was not affected by the addition of the polymer. Indeed, pure MPO and MPO with 3\%wt of PMAEO showed Newtonian behaviors as the dynamic viscosity remained constant with the shear rate for both cases. The dynamic viscosities at $50 \mathrm{~s}^{-1}$ shear rate are $42.9 \mathrm{mPa} . \mathrm{s}$ and $47.2 \mathrm{mPa} . \mathrm{s}$ for respectively pure MPO and MPO with $3 \%$ wt of PMAEO compared to 41.7 and $46.5 \mathrm{mPa}$.s at $1,000 \mathrm{~s}^{-1}$ shear rate. In addition, the plot of shear stress against shear rate showed a straight line that passed through the origin with a constant slope for both solutions. This behavior is also characteristic of Newtonians fluids as they do not require any yield stress to flow (intercept of $y$-axis closed to zero $\mathrm{Pa}$ ). Therefore, it can be deduced that PMAEO addition did not negatively affect the flow behavior of MPO at $20^{\circ} \mathrm{C}$.

On the other hand, MPO showed disturbed flow on chilling with a non-Newtonian behavior at $-30^{\circ} \mathrm{C}$ (Erreur! Source du renvoi introuvable.). For instance, the dynamic viscosity showed significant variation with shear rate; at $50 \mathrm{~s}^{-1}$ shear rate, the dynamic viscosity was $8470 \mathrm{mPa}$.s while at $600 \mathrm{~s}^{-1}$, it was $1973 \mathrm{mPa}$.s. Furthermore, the plot of shear stress against shear rate did not pass through the origin, which demonstrated that pure MPO required a specific high yield stress to flow properly (309 Pa). Thus, this fluid can be assigned to a Bingham plastic fluid at low temperature. As previously mentioned, this disturbed flowing is related to the appearance of solid wax particles in MPO combined with an increasing oil viscosity with decreasing temperature and thus induced a disturbed flowing. Nevertheless, when MPO is mixed with $3 \%$ wt of PMAEO, the oilpolymer blend showed different rheological behavior. As it is shown in Figure 8, doped MPO had a lower dynamic viscosity compared to the pure MPO. For instance, at $150 \mathrm{~s}^{-1}$ shear rate, the doped MPO had a dynamic viscosity of $1980 \mathrm{mPa}$ whereas the pure MPO had a higher dynamic viscosity of 3396 $\mathrm{mPa}$.s. Furthermore, doped MPO dynamic viscosities were less sensitive to the increase of shear rate compared to pure MPO. Indeed, the values of dynamic viscosity for pure MPO and doped MPO are respectively 8470 and $2045 \mathrm{mPa}$.s at $150 \mathrm{~s}^{-1}$ shear rate and 1973 and $1883 \mathrm{mPa} . \mathrm{s}$ at $600 \mathrm{~s}^{-1}$. In addition, according to the value of the intercept with $y$-axis of the plot of shear stress versus shear rate, the required yield stress to set $\mathrm{MPO}$ in motion with $3 \% \mathrm{wt}$ of PMAEO was much lower (42 $\mathrm{Pa})$ than the one required for pure MPO (309 $\mathrm{Pa})$. Therefore, it can be deducted that the MPO flow is considerably enhanced at $-30{ }^{\circ} \mathrm{C}$ by the polymer addition. The mechanism of action of these polymers in such oils is not well understood yet but they can somehow mitigate the formation of wax crystals which naturally occur in oil with chilling and disturb the flow by solidifying the oil. ${ }^{53}$ According to the literature, the polymer with linear hydrophobic side chains can interact with the long paraffin chains in the oil due to their similar structure while their polar part, dissimilar to the paraffin crystals, has the ability to block the extensive wax crystallization by creating steric hindrance between crystal agglomerates. ${ }^{54}$ As a result, the precipitation of paraffinic chain in oil is delayed and the oil viscosity is reduced inducing an improvement of oil cold flow properties.

\section{Conclusions}

MAEO was synthesized by reacting oleic acid and HEMA to afford a comb-like polymer via radical process (PMAEO) as partially bio-based viscosity modifier for lubricating oils. Viscosimetric characterizations of oil-polymer blends revealed two different viscosity behaviors of PMAEO coil with temperature depending on its oil affinity. In a first part, PMAEO showed coil expansion with temperature when added in MPO inducing a better viscosity contribution at higher temperature. The limited solubility of PMAEO in MPO at low temperature was attributed to the high content of hydrocarbons in oil which do not have any affinity with the ester functionality contained in the PMAEO backbone. These results are in total accordance with the common mechanism of action of PAMA viscosity control additive in lubricating mineral oils.

On the contrary, PMAEO has a similar structure than triglycerides contained in OTO inducing a high 
solubility even at low temperature. Hence, the polymer coil size dimension was not improved with temperature even for high polymer concentrations. Thereby, the behavior of PMAEO in OTO can be defined as a thickener additive.

In a second part, rheological studies showed that addition of PMAEO in MPO could also improved initial oil cold flow at low temperature by reducing the required yield stress to put the fluid in motion. In conclusion, these results confirmed that PMAEO represents an interesting bio-alternative rheological additive improver to conventional PAMA in mineral oil by exhibiting the ability to improve operating temperature range of MPO either at low than at high temperature.

\section{Acknowledgment}

This work was performed, in partnership with the SAS PIVERT, within the frame of the French Institute for the Energy Transition (Institut pour la Transition Energétique (ITE) P.I.V.E.R.T. (www.institutpivert.com) selected as an Investment for the Future ("Investissements d'Avenir"). This work was supported, as part of the Investments for the Future, by the French Government under the reference ANR001-01.

The authors have declared no conflict of interest.

\section{References}

(1) Gandini, A. Polymers from Renewable Resources: A Challenge for the Future of Macromolecular Materials. Macromolecules 2008, 41 (24), 9491-9504.

(2) Faessler, P.; Kolmetz, K.; Seang, K. W.; Lee, S. $\mathrm{H}$. Advanced Fractionation Technology for the Oleochemical Industry. Asia-Pac. J. Chem. Eng. 2007, 2 (4), 315-321.

(3) Abdelmoez, W.; Mustafa, A. Oleochemical Industry Future through Biotechnology. J. Oleo Sci. 2014, 63 (6), 545-554.

(4) Lligadas, G.; Ronda, J. C.; Galià, M.; Cádiz, V. Renewable Polymeric Materials from Vegetable Oils: A Perspective. Mater. Today 2013, 16 (9), 337-343.

(5) Salimon, J.; Salih, N.; Yousif, E. Industrial Development and Applications of Plant Oils and Their Biobased Oleochemicals. Arab. J. Chem. 2012, 5 (2), 135-145.

(6) Biermann, U.; Friedt, W.; Lang, S.; Lühs, W.; Machmüller, G.; Metzger, J. O.; Ruesch gen Klaas, M.; Schaefer, H. J.; Schneider, M. P. New Syntheses with Oils and Fats as Renewable Raw Materials for the Chemical Industry. Angew. Chem. Int. Ed. 2000, 39 (13), 2206-2224.

(7) Maisonneuve, L.; Chollet, G.; Grau, E.; Cramail, H. Vegetable Oils: A Source of Polyols for Polyurethane Materials. $\mathrm{OCL}$ 2016, 23 (5), D508.

(8) Fertier, L.; Koleilat, H.; Stemmelen, M.; Giani, O.; Joly-Duhamel, C.; Lapinte, V.; Robin, J.-J. The Use of Renewable Feedstock in UV-Curable Materials - A New Age for Polymers and Green Chemistry. Prog. Polym. Sci. 2013, 38 (6), 932-962.

(9) Pham, P. D.; Monge, S.; Lapinte, V.; Raoul, Y.; Robin, J. J. Various Radical Polymerizations of Glycerol-Based Monomers. Eur. J. Lipid Sci. Technol. 2013, 115 (1), 28-40.

(10) Dworakowska, S.; Bogdał, D.; Zaccheria, F.; Ravasio, N. The Role of Catalysis in the Synthesis of Polyurethane Foams Based on Renewable Raw Materials. Catal. Today 2014, 223, 148-156.

(11) Paramarta, A.; Webster, D. C. The Exploration of Michael-Addition Reaction Chemistry to Create High Performance, Ambient Cure Thermoset Coatings Based on Soybean Oil. Prog. Org. Coat. 2017, 108, 5967.

(12) Montero de Espinosa, L.; Meier, M. A. R. Plant Oils: The Perfect Renewable Resource for Polymer Science?! Eur. Polym. J. 2011, 47 (5), 837-852.

(13) Pham, P. D.; Lapinte, V.; Raoul, Y.; Robin, J.-J. Lipidic Polyols Using Thiol-Ene/Yne Strategy for Crosslinked Polyurethanes. J. Polym. Sci. Part Polym. Chem. 2014, 52 (11), 15971606.

(14) Desroches, M.; Caillol, S.; Lapinte, V.; Auvergne, R.; Boutevin, B. Synthesis of Biobased Polyols by Thiol-Ene Coupling from Vegetable Oils. Macromolecules 2011, 44 (8), 2489-2500. 
(15) Stemmelen, M.; Pessel, F.; Lapinte, V.; Caillol, S.; Habas, J.-P.; Robin, J.-J. A Fully Biobased Epoxy Resin from Vegetable Oils: From the Synthesis of the Precursors by Thiol-Ene Reaction to the Study of the Final Material. J. Polym. Sci. Part Polym. Chem. 2011, 49 (11), 2434-2444.

(16) Dworakowska, S.; Cornille, A.; Bogdat, D.; Boutevin, B.; Caillol, S. Formulation of BioBased Epoxy Foams from Epoxidized Cardanol and Vegetable Oil Amine: Cardanol-Based Epoxy Foams. Eur. J. Lipid Sci. Technol. 2015, 117 (11), 1893-1902.

(17) Desroches, M.; Benyahya, S.; Besse, V.; Auvergne, R.; Boutevin, B.; Caillol, S. Synthesis of Bio-based Building Blocks from Vegetable Oils: A Platform Chemicals Approach. Lipid Technol. 2014, 26 (2), 35-38.

(18) Lligadas, G.; Ronda, J. C.; Galià, M.; Cádiz, V. Renewable Polymeric Materials from Vegetable Oils: A Perspective. Mater. Today 2013, 16 (9), 337-343.

(19) Adekunle, K. F. A Review of Vegetable OilBased Polymers: Synthesis and Applications. Open J. Polym. Chem. 2015, 05 (03), 34-40.

(20) Ali, U.; Karim, K. J. B. A.; Buang, N. A. A Review of the Properties and Applications of Poly (Methyl Methacrylate) (PMMA). Polym. Rev. 2015, 55 (4), 678-705.

(21) Heinzmann, C.; Salz, U.; Moszner, N.; Fiore, G. L.; Weder, C. Supramolecular Cross-Links in Poly(Alkyl Methacrylate) Copolymers and Their Impact on the Mechanical and Reversible Adhesive Properties. ACS Appl. Mater. Interfaces 2015, 7 (24), 1339513404.

(22) López, A. B.; de la Cal, J. C.; Asua, J. M. Highly Hydrophobic Coatings from Waterborne Latexes. Langmuir 2016, 32 (30), 7459-7466.

(23) Cai, G.; Zhang, L.; Ma, L.; Eli, W. Synthesis and Characterization of Polybutylacrylate Viscosity Index Improver with Anti-Wear Function: A NEW ANTI-WEAR POLYBUTYLACRYLATE VII WAS PREPARED AND EVALUATED. Lubr. Sci. 2015, 27 (4), 209-216.

(24) Morgan, S.; Ye, Z.; Subramanian, R.; Zhu, S. Higher-molecular-weight Hyperbranched Polyethylenes Containing Crosslinking
Structures as Lubricant Viscosity-index Improvers. Polym. Eng. Sci. 2010, 50 (5), 911-918.

(25) Selby, T. W. The Non-Newtonian Characteristics of Lubricating Oils. E Trans. 1958, 1 (1), 68-81.

(26) Covitch, M. J.; Trickett, K. J. How Polymers Behave as Viscosity Index Improvers in Lubricating Oils. Adv. Chem. Eng. Sci. 2015, 05 (02), 134-151.

(27) Ghosh, P.; Hoque, M.; Karmakar, G.; Das, M. K. Dodecyl Methacrylate and Vinyl Acetate Copolymers as Viscosity Modifier and Pour Point Depressant for Lubricating Oil. Int. J. Ind. Chem. 2017, 8 (2), 197-205.

(28) Soldi, R. A.; Oliveira, A. R. S.; Barbosa, R. V.; César-Oliveira, M. A. F. Polymethacrylates: Pour Point Depressants in Diesel Oil. Eur. Polym. J. 2007, 43 (8), 3671-3678.

(29) Binks, B. P.; Fletcher, P. D. I.; Roberts, N. A.; Dunkerley, J.; Greenfield, H.; Mastrangelo, A.; Trickett, K. How Polymer Additives Reduce the Pour Point of Hydrocarbon Solvents Containing Wax Crystals. Phys Chem Chem Phys 2015, 17 (6), 4107-4117.

(30) El Gamal; Atta; Al-Sabbagh. Polymeric Structures as Cold Flow Improvers for Waxy Residual Fuel Oil. 1997.

(31) Roenningsen, H. P.; Bjoerndal, B.; Baltzer Hansen, A.; Batsberg Pedersen, W. Wax Precipitation from North Sea Crude Oils: 1. Crystallization and Dissolution

Temperatures, and Newtonian and NonNewtonian Flow Properties. Energy Fuels 1991, 5 (6), 895-908.

(32) Pedersen, K. S.; Rønningsen, H. P. Influence of Wax Inhibitors on Wax Appearance Temperature, Pour Point, and Viscosity of Waxy Crude Oils. Energy Fuels 2003, 17 (2), 321-328.

(33) Dubois, J. L.; Patience, G. Method for Preparing Acrylic Acid from Glycerol; Google Patents, 2012.

(34) Upadhyay, M.; Karmakar, G.; Kapur, G. S.; Ghosh, P. Multifunctional Greener Additives for Lubricating Oil. Polym. Eng. Sci. 2017.

(35) Moreno, M.; Goikoetxea, M.; Barandiaran, M. J. Biobased-Waterborne Homopolymers from Oleic Acid Derivatives. J. Polym. Sci. 
Part Polym. Chem. 2012, 50 (22), 4628-

4637.

(36) Bunker, S. P.; Wool, R. P. Synthesis and Characterization of Monomers and Polymers for Adhesives from Methyl Oleate. J. Polym.

Sci. Part Polym. Chem. 2002, 40 (4), 451458.

(37) Maiti, B.; Kumar, S.; De, P. Controlled RAFT Synthesis of Side-Chain Oleic Acid Containing Polymers and Their Post-Polymerization Functionalization. RSC Adv 2014, 4 (99), 56415-56423.

(38) Cho, H.-G.; Park, S.-Y.; Jegal, J.; Song, B.-K.; Kim, H.-J. Preparation and Characterization of Acrylic Polymers Based on a Novel Acrylic Monomer Produced from Vegetable Oil. J. Appl. Polym. Sci. 2009, n/a-n/a.

(39) Campanella, A.; Rustoy, E.; Baldessari, A.; Baltanás, M. A. Lubricants from Chemically Modified Vegetable Oils. Bioresour. Technol. 2010, 101 (1), 245-254.

(40) Moreno, M.; Goikoetxea, M.; de la Cal, J. C.; Barandiaran, M. J. From Fatty Acid and Lactone Biobased Monomers toward Fully Renewable Polymer Latexes. J. Polym. Sci. Part Polym. Chem. 2014, n/a-n/a.

(41) Eren, T.; Küsefoğlu, S. H. Synthesis and Polymerization of the Bromoacrylated Plant Oil Triglycerides to Rigid, Flame-Retardant Polymers. J. Appl. Polym. Sci. 2004, 91 (4), 2700-2710.

(42) Maiti, B.; De, P. RAFT Polymerization of Fatty Acid Containing Monomers: Controlled Synthesis of Polymers from Renewable Resources. RSC Adv. 2013, 3 (47), 2498324990.

(43) Vingering, N.; Oseredczuk, M.; du Chaffaut, L.; Ireland, J.; Ledoux, M. Fatty Acid Composition of Commercial Vegetable Oils from the French Market Analysed Using a Long Highly Polar Column. Ol. Corps Gras Lipides 2010, 17, 185-192.

(44) Al-Shafey, H. I.; Hashem, A. I.; Hameed, R. A.; Dawood, E. A. Studies on the Influence of Long Chain Acrylic Esters Co-Polymers Grafted With Vinyl Acetate as Flow Improver Additives of Crude Oils. Adv. Appl. Sci. Res. 2011, 2 (5), 476-489.
(45) Al-Sabagh, A. M.; Noor El-Din, M. R.; Morsi, R. E.; Elsabee, M. Z. Styrene-Maleic Anhydride Copolymer Esters as Flow Improvers of Waxy Crude Oil. J. Pet. Sci. Eng. 2009, 65 (3-4), 139-146.

(46) Wu, Y.; Ni, G.; Yang, F.; Li, C.; Dong, G. Modified Maleic Anhydride Co-Polymers as Pour-Point Depressants and Their Effects on Waxy Crude Oil Rheology. Energy Fuels 2012, 26 (2), 995-1001.

(47) Garcia, M. del C.; Carbognani, L.; Urbina, A.; Orea, M. Paraffin Deposition in Oil Production. Oil Composition and Paraffin Inhibitors Activity. Pet. Sci. Technol. 1998, 16 (9-10), 1001-1021.

(48) Neveu, C. D.; Sondjaja, R.; Stöhr, T.; Iroff, N. J. Lubricant and Fuel Additives Based on Polyalkylmethacrylates. In Polymer Science: A Comprehensive Reference; Elsevier, 2012; pp 453-478.

(49) Ahmed, N. S.; Nassar, A. M.; Nasser, R. M.; Khattab, A. F.; Abdel-Azim, A.-A. A. Synthesis and Evaluation of Some Polymeric Compounds as Pour Point Depressants and Viscosity Index Improvers for Lube Oil. Pet. Sci. Technol. 2008, 26 (12), 1390-1402.

(50) Al-Sabagh, A. M.; Khalil, T. M.; Sabaa, M. W.; Khidr, T. T.; Saad, G. R. Poly(n-Alkyl Itaconate-Co-Vinyl Acetate) as Pour Point Depressants for Lube Oil in Relation to Rheological Flow Properties. J. Dispers. Sci. Technol. 2012, 33 (11), 1649-1660.

(51) Synthesis of Polymeric Pour Point Depressants for Nada Crude Oil (Gujarat, India) and Its Impact on Oil Rheology. Fuel Process. Technol. 2008, 89 (3), 227-233.

(52) Torres, E.; Dutta, N.; Choudhury, N. R.; Matisons, J. Effect of Composition on the Solution Rheology of Stearyl Methacrylate-co-styrene-co-vinyl Pyrrolidinone in Paraffinic Base Oil. Polym. Eng. Sci. 2004, 44 (4), 736-748.

(53) Yang, F.; Zhao, Y.; Sjöblom, J.; Li, C.; Paso, K. G. Polymeric Wax Inhibitors and Pour Point Depressants for Waxy Crude Oils: A Critical Review. J. Dispers. Sci. Technol. 2015, 36 (2), 213-225. 
(54) Martini, A.; Ramasamy, U. S.; Len, M. Review of Viscosity Modifier Lubricant Additives.

Tribol. Lett. 2018, 66 (2), 58.

\section{Figure Captions}

Figure 1: ${ }^{1} \mathrm{H}$ NMR spectrums of MAEO (A) and PMAEO (B) in $\mathrm{CDCl}_{3}$

Figure 2: ${ }^{1} \mathrm{H}$ NMR monitoring of MAEO monomer conversion vs reaction time

Figure 3: Relative viscosity vs temperature in MPO at various polymer concentrations

Figure 4: Reduced viscosity vs PMAEO concentrations in $\mathrm{MPO}$ at $40^{\circ} \mathrm{C}$ and $100^{\circ} \mathrm{C}$

Figure 5: Relative viscosity vs temperature in OTO at various polymer concentrations

Figure 6: Coil expansion mechanism

Figure 7: Shear stress (Pa, $\boldsymbol{M} \mathrm{MPO} ; \boldsymbol{\Delta} \mathrm{MPO}+3 \%$ wt of PMAEO) and dynamic viscosity (mPa.s, $\bullet$ MPO ; $\star$ MPO $+3 \%$ wt of PMAEO) vs shear rate $(\mathrm{s}-1)$ at $-20^{\circ} \mathrm{C}$

Figure 8: Shear stress (Pa, $\square \mathrm{MPO} ; \boldsymbol{\Delta} \mathrm{MPO}+3 \%$ wt of PMAEO) and dynamic viscosity (mPa.s, $\bullet \mathrm{MPO} ; \star$ MPO $+3 \%$ wt of PMAEO) vs shear rate $(\mathrm{s}-1)$ at $-30^{\circ} \mathrm{C}$

Scheme 1: (A) Synthesis of MAEO by Steglich esterification of oleic acid ; (B) Synthesis of PMAEO by free radical polymerization

Table 1: Viscosimetric properties of oils at different temperatures

Table 2: Kinematic viscosity data of various oil-polymer blends with temperature 